\title{
Journal of Nephrology
}

\section{Osteocalcin (bone GLA protein) levels, vascular calcifications, vertebral fractures and mortality in hemodialysis patients with diabetes mellitus. --Manuscript Draft--}

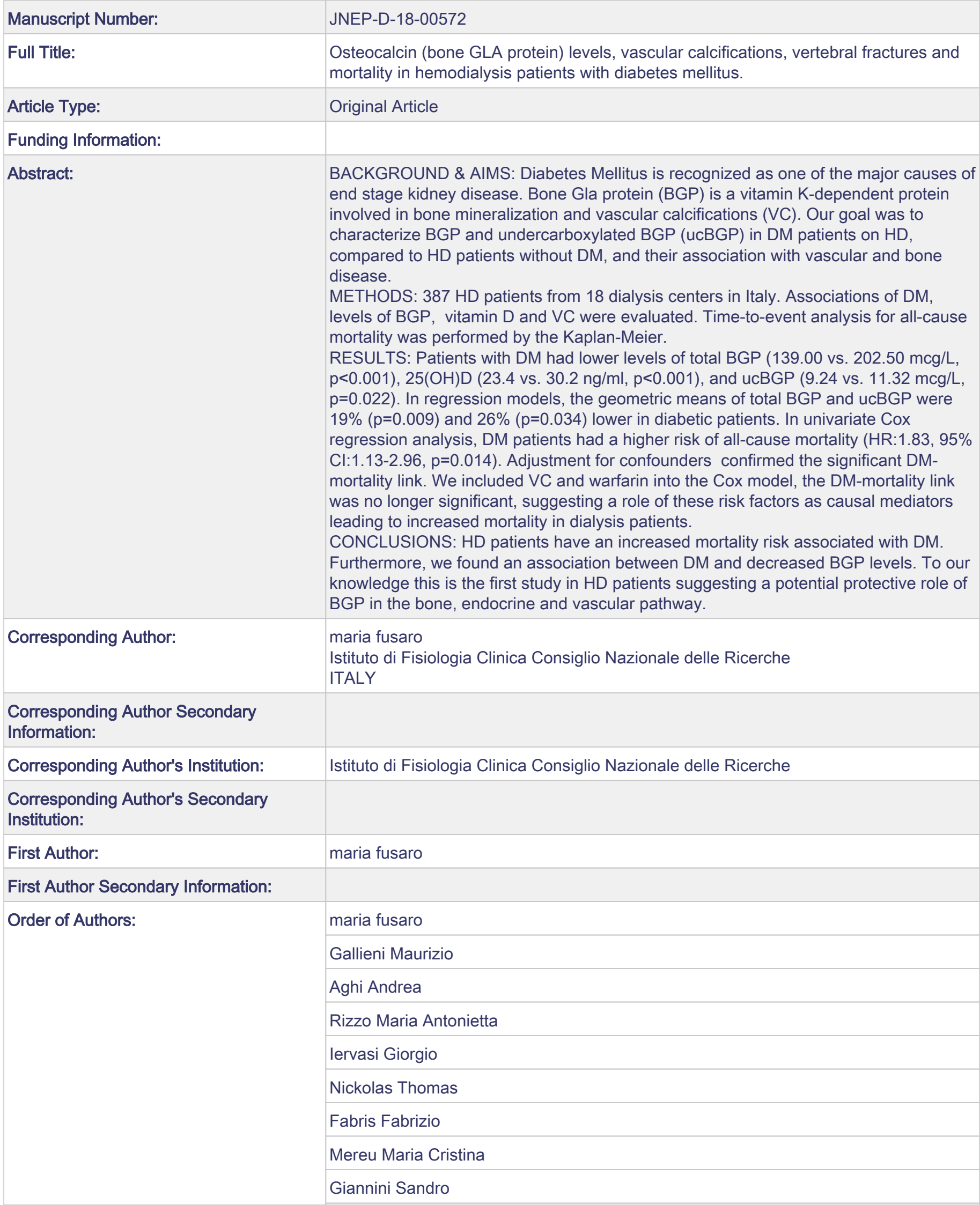




\begin{tabular}{|c|c|}
\hline & Sella Stefania \\
\hline & Giusti Andrea \\
\hline & Pitino Annalisa \\
\hline & D'Arrigo Graziella \\
\hline & Rossini Maurizio \\
\hline & Gatti Davide \\
\hline & Ravera Maura \\
\hline & Di Lullo Luca \\
\hline & Bellasi Antonio \\
\hline & Brunori Giuliano \\
\hline & Piccoli Antonio \\
\hline & Tripepi Giovanni \\
\hline & Plebani Mario \\
\hline Order of Authors Sec & \\
\hline Author Comments: & $\begin{array}{l}\text { Padua, } 14 \text { October } 2018 \\
\text { To Editor, Journal of Nephrology } \\
\text { Dear Editor, } \\
\text { herewith you find the manuscript Osteocalcin (bone GLA protein) levels, vascular } \\
\text { calcifications, vertebral fractures and mortality in hemodialysis patients with diabetes } \\
\text { mellitus, which I submit for publication as an original article in the Journal of } \\
\text { Nephrology. } \\
\text { Diabetes Mellitus (DM) is one of the major causes of end stage kidney disease. } \\
\text { Patients with DM and Chronic kidney disease (CKD) have greater severity of CKD } \\
\text { associated complications, in particular, they are inclined to micro and macro-vascular } \\
\text { complications, and earlier and progressive bone disorders, such as osteoporosis, } \\
\text { adynamic bone disease and fractures. } \\
\text { Bone Gla Protein (BGP or osteocalcin, OC) is a vitamin K-dependent protein, secreted } \\
\text { by osteoblasts and involved in the regulation of bone matrix mineralization. Levels of } \\
\text { BGP in DM patients on hemodialysis (HD) have been poorly described. Our goal was } \\
\text { to characterize BGP and ucBGP in DM patients on HD, compared to HD patients } \\
\text { without DM, and their association with vascular and bone disease. To our knowledge, } \\
\text { this is the first study in hemodialysis patients suggesting a potential protective role of } \\
\text { BGP in the context of bone, endocrine and vascular pathway. } \\
\text { The general message is the need to pay attention to vitamin K levels to prevent bone } \\
\text { and vascular damage both in general population and in CKD patients, especially in DM } \\
\text { CKD patients. Indeed we hope that our findings will raise awareness and inspire other } \\
\text { physicians to carry out research about the importance of vitamin K and its Vitamin K } \\
\text { Dependet Proteins in the development of vascular calcification and bone fractures, } \\
\text { both risk factors for the main cause of morbidity and mortality. } \\
\text { The paper is original and is not under consideration by any other journal. } \\
\text { Thanking you for your attention. } \\
\text { Yours sincerely } \\
\text { Maria Fusaro, MD, PhD }\end{array}$ \\
\hline Suggested Reviewer & \\
\hline
\end{tabular}


Padua, 14 October 2018

\section{To Editor, Journal of Nephrology}

Dear Editor, herewith you find the manuscript Osteocalcin (bone GLA protein) levels, vascular calcifications, vertebral fractures and mortality in hemodialysis patients with diabetes mellitus, which I submit for publication as an original article in the Journal of Nephrology.

Diabetes Mellitus (DM) is one of the major causes of end stage kidney disease. Patients with DM and Chronic kidney disease (CKD) have greater severity of CKD associated complications, in particular, they are inclined to micro and macro-vascular complications, and earlier and progressive bone disorders, such as osteoporosis, adynamic bone disease and fractures.

Bone Gla Protein (BGP or osteocalcin, OC) is a vitamin K-dependent protein, secreted by osteoblasts and involved in the regulation of bone matrix mineralization. Levels of BGP in DM patients on hemodialysis (HD) have been poorly described. Our goal was to characterize BGP and ucBGP in DM patients on HD, compared to HD patients without DM, and their association with vascular and bone disease. To our knowledge, this is the first study in hemodialysis patients suggesting a potential protective role of BGP in the context of bone, endocrine and vascular pathway.

The general message is the need to pay attention to vitamin $\mathrm{K}$ levels to prevent bone and vascular damage both in general population and in CKD patients, especially in DM CKD patients. Indeed we hope that our findings will raise awareness and inspire other physicians to carry out research about the importance of vitamin K and its Vitamin K Dependet Proteins in the development of vascular calcification and bone fractures, both risk factors for the main cause of morbidity and mortality.

The paper is original and is not under consideration by any other journal.

Thanking you for your attention.

Yours sincerely

Maria Fusaro, MD, PhD 
Osteocalcin (bone GLA protein) levels, vascular calcifications, vertebral fractures and mortality in hemodialysis patients with diabetes mellitus.

Fusaro M. ${ }^{1,2}$, Gallieni M. ${ }^{3}$, Aghi A. ${ }^{4}$, Rizzo MA. ${ }^{5}$, Iervasi G. ${ }^{1}$, Nickolas TL. ${ }^{6}$, Fabris F. ${ }^{4}$, Mereu MC. ${ }^{7}$, Giannini S. ${ }^{4}$, Sella S. ${ }^{4}$, Giusti A. ${ }^{8}$, Pitino A. ${ }^{1}$, D’Arrigo G. ${ }^{9}$, Rossini M. ${ }^{10}$, Gatti D. ${ }^{10}$, Ravera M. ${ }^{11}$, Di Lullo L. ${ }^{12}$, Bellasi A. ${ }^{13}$, Brunori G. ${ }^{14}$, Piccoli A. ${ }^{15}$, Tripepi G. ${ }^{9}$ \& Plebani M. ${ }^{16}$

${ }^{1}$ National Research Council (CNR) - Institute of Clinical Physiology (IFC), Pisa Via G. Moruzzi 1, 56124, Pisa, PI, Italy.

${ }^{2}$ Department of Medicine, University of Padova Italy; Via Giustiniani 2, 35128, Padova, PD, Italy.

${ }^{3}$ Nephrology and Dialysis Unit, Department of Clinical and Biomedical Sciences 'Luigi Sacco', University of Milan, Milan, Italy.

${ }^{4}$ Department of Medicine, Clinica Medica 1, University of Padova, Padova, Italy.

${ }^{5}$ Nephrology and Dialysis Unit, Ospedale di Circolo di Busto Arsizio, ASST Valle Olona, Italy.

${ }^{6}$ Department of Medicine, Division of Nephrology, Columbia University Medical Center, New York, New York.

${ }^{7}$ Nephrologist independent researcher, Cagliari.

${ }^{8}$ Bone Clinic, Dipartimento delle Cure Geriatriche, Ortogeriatria e Riabilitazione, Ospedale Galliera, Genova, Italia.

${ }^{9}$ Clinical Epidemiology and Physiopathology of Renal Diseases and Hypertension, CNR, Institute of Clinical Physiology, Reggio Calabria, Calabria, Italy.

${ }^{10}$ Rheumatology Unit, Department of Medicine, University of Verona and Regional Center for Osteoporosis, Verona, Italy.

${ }^{11}$ Department of Nephrology and Dialysis, S. Martino Hospital, Genoa, Italy.

${ }^{12}$ Department of Nephrology and Dialysis, Parodi-Delfino Hospital, Colleferro, Italy.

${ }^{13}$ Department of Nephrology and Dialysis, S. Anna Hospital, ASST Lariana, Como, Italy.

${ }^{14}$ SC Multizonale di Nefrologia e Dialisi, APSS, Trento, Italia.

${ }^{15}$ Nephrology Unit, University of Padua, Padua, Italy.

${ }^{16}$ Laboratory Medicine Unit, Department of Medicine, University of Padova, Padova, Italy.

Acknowledgments: We thank the VIKI Study Investigators, who provided patient clinical care and collected clinical data.

Keywords: Diabetes Mellitus, BGP, Vitamin K, hemodialysis. 
Corresponding Author:

Maria Fusaro, MD, PhD

National Research Council (CNR) - Institute of Clinical Physiology (IFC), Pisa

Via G. Moruzzi 1, 56124, Pisa, PI, Italy.

and

Department of Medicine, University of Padua, Italy;

Via Giustiniani 2, 35128, Padova, PD, Italy.

dante.lucia@libero.it 
1 Osteocalcin (bone GLA protein) levels, vascular calcifications, vertebral fractures and 2 mortality in hemodialysis patients with diabetes mellitus.

3 ABSTRACT

4 BACKGROUND \& AIMS: Diabetes Mellitus is recognized as one of the major causes of end stage 5 kidney disease. Bone Gla protein (BGP) is a vitamin K-dependent protein involved in bone 6 mineralization and vascular calcifications (VC). Our goal was to characterize BGP and 7 undercarboxylated BGP (ucBGP) in DM patients on HD, compared to HD patients without DM, and 8 their association with vascular and bone disease. METHODS: 387 HD patients from 18 dialysis centers in Italy. Associations of DM, levels of BGP, vitamin D and VC were evaluated. Time-to-event analysis for all-cause mortality was performed by the Kaplan-Meier. RESULTS: Patients with DM had lower levels of total BGP (139.00 vs. $202.50 \mathrm{mcg} / \mathrm{L}, \mathrm{p}<0.001)$, 25(OH)D (23.4 vs. $30.2 \mathrm{ng} / \mathrm{ml}, \mathrm{p}<0.001)$, and ucBGP (9.24 vs. $11.32 \mathrm{mcg} / \mathrm{L}, \mathrm{p}=0.022)$. In regression models, the geometric means of total BGP and ucBGP were 19\% (p=0.009) and 26\% (p=0.034) lower in diabetic patients. In univariate Cox regression analysis, DM patients had a higher risk of all-cause mortality (HR:1.83, 95\% CI:1.13-2.96, p=0.014). Adjustment for confounders confirmed the significant DM-mortality link. We included VC and warfarin into the Cox model, the DM-mortality link was no longer significant, suggesting a role of these risk factors as causal mediators leading to increased mortality in dialysis patients.

CONCLUSIONS: HD patients have an increased mortality risk associated with DM. Furthermore, we found an association between DM and decreased BGP levels. To our knowledge this is the first study in HD patients suggesting a potential protective role of BGP in the bone, endocrine and vascular pathway. 


\section{Introduction}

Diabetes Mellitus (DM) is one of the major causes of end stage kidney disease. Patients with DM and Chronic kidney disease (CKD) have greater severity of CKD associated complications compared to CKD patients with other etiologies of kidney disease. In particular, DM patients are inclined to micro and macro-vascular complications, and earlier and progressive bone disorders, such as osteoporosis, adynamic bone disease and fractures (1).

Bone Gla Protein (BGP or osteocalcin, OC) is a vitamin K-dependent protein, secreted by osteoblasts and involved in the regulation of bone matrix mineralization. Carboxylated osteocalcin (Glacontaining cBGP) is involved in bone crystal nucleation by its specific affinity to bind hydroxyapatite molecules. In contrast, ucBGP (ucBGP or ucOC) has less than 3 carboxylated residues and a lower affinity for bone tissue. An endocrine role of ucOC has been recently identified (2, 3). It seems to be able to increase insulin secretion directly by stimulating pancreatic $\beta$ cells, or indirectly by promoting the release of adiponectin (4).

BGP also has a protective role in vascular calcifications in humans (5), acting under the genetic control of vitamin D. Vitamin D deficiency is highly prevalent in CKD patients, suggesting that the protective role of vitamin D on vascular calcification (6) may be mediated by a reduced expression of BGP and other vitamin $\mathrm{K}$ dependent proteins involved in calcification pathways, such as Matrix Gla Protein, a potent inhibitor of vascular calcifications (7).

Levels of BGP in DM patients on hemodialysis (HD) have been poorly described. Therefore, our goal was to characterize BGP and ucBGP in DM patients on HD, compared to HD patients without DM, and their association with vascular and bone disease.

\section{Methods}

We performed a secondary analysis of the VIKI (VItamin K Italian) study (8), involving 387 hemodialysis patients from 18 dialysis centers in Italy. Local ethics committees approved the study. Inclusion criteria were both genders, on hemodialysis for $>1$ year, and their written informed consent; exclusion criteria were patients with life expectancy $<6$ months, diagnosis of cancer (with the exception of basal cell carcinoma), coagulation disorders, or conditions potentially interfering with study outcomes.

Data on DM were collected in 85 patients. We reported general features, type of dialysis, comorbidities and biochemical profiles. 
Serum PTH was measured by automated LIAISON® N-Tact ${ }^{\circledR}$ PTH Assay 310910 (DiaSorin Inc., carried out on the LIAISON ${ }^{\circledR}$ (DiaSorin Inc., Stillwater MN, USA) instrument. The analytical sensitivity is $1 \mathrm{pg} / \mathrm{mL}$ and the intra-assay and inter-assay CVs were 3.7-6.3 and 3.5-5.3\%, respectively.

\section{5-OH Vitamin D}

For quantitative determination of total $25-\mathrm{OH}$ vitamin $\mathrm{D}$ (both $\mathrm{D}_{2}$ and $\mathrm{D}_{3}$ form) in serum, we used the automated LIAISON ${ }^{\circledR} 25$ OH Vitamin D TOTAL Assay 310600, a direct competitive CLIA executed on the LIAISON (DiaSorin Inc., Stillwater MN, USA) instrument. The analytical sensitivity is $<10 \mathrm{nmol} / \mathrm{L}$, and the intra-assay coefficients of variation $(\mathrm{CV})$ were between 2.9 and $5.5 \%$, while the inter-assay $\mathrm{CV}$ is $6.3-12.9 \%$.

\section{Total BGP}

The method for the quantitative determination of total BGP in serum was the automated LIAISON ${ }^{\circledR}$ Osteocalcin Assay 310950 (DiaSorin Inc., Stillwater MN, USA), a direct, 2-site, sandwich-type CLIA executed on the LIAISON ${ }^{\circledR}$ (DiaSorin Inc., Stillwater MN, USA) instrument. The analytical sensitivity is $<0.3 \mathrm{ng} / \mathrm{mL}$ and the intra-assay $\mathrm{CV}$ is $3-8 \%$, while the inter-assay $\mathrm{CV}$ is $4-9 \%$.

\section{Undercarboxylated BGP (ucBGP)}

For quantitative determination of ucBGP, we used the Glu-osteocalcin Enzyme Immunoassay (EIA) Kit MK118 (Takara Bio Inc., Otsu, Shiga, Japan), a manual solid-phase EIA based on a sandwich method that utilizes 2 mouse monoclonal anti-ucBGP antibodies to detect ucBGP by a 2-step procedure. One of the mouse monoclonal anti-undercarboxylated BGPs is immobilized onto the micro-titre plate and blocked against non-specific binding. Samples are added to each well and incubated. The second step is to wash the plate and to add the second anti-BGP labelled with peroxidase (POD). The reaction between POD and substrate $\left(\mathrm{H}_{2} \mathrm{O}_{2}\right.$ and 3,3', 5,5' tetramethylbenzidine) results in color development with intensities proportional to the amount of ucBGP present. The analytical sensitivity is $0.25 \mathrm{ng} / \mathrm{mL}$ and the intra-assay and inter-assay CVs are 4.4-6.7 and 5.7$9.9 \%$, respectively. 
The quantitative determination of MGP was performed using the Human MGP-Matrix Gla Protein Kit (Biomedica Medizinprodukte GmbH \& Co KG, Wien, A). It is a manual competitive ELISA method designed to detect MGP in serum. The analytical sensitivity is $0.3 \mathrm{nmol} / \mathrm{L}$, and the intra-assay and inter-assay coefficients of variation (CVs) are 5-6 and 7-9\%, respectively.

\section{Undercarboxylated MGP (ucMGP)}

The measurement of the total undercarboxylated Matrix GLA Protein was performed by VitaK using a competitive ELISA, as described previously (9). The analytical sensitivity is $21 \mathrm{nmol} / \mathrm{L}$, and the intra-assay and inter-assay CVs have been found to be 8.9 and $11.4 \%$, respectively.

\section{Statistical analysis}

Normally distributed data were summarized as mean \pm standard deviation (SD), non-normally distributed data as median and interquartile range (IQR), and binary/categorical data as percentages, as appropriate. Categorical variables between two groups were compared by $\chi^{2}$ test or Fisher's exact method. The comparison between medians was performed by the Mann-Whitney rank test whereas means were compared by unpaired T-Test.

To assess associations between log transformed values of total and ucBGP (outcome variables) and diabetes mellitus two multiple linear regression models were built. Variables available for the analysis were: gender, age, renal failure history, alcohol consumption, medical history (cardio and cerebrovascular disease, diabetes mellitus, malabsorption syndrome and liver disease), BMI, routine biochemical examinations, and mineral and bone disorders treatment (oral calcitriol, vitamin D analogues, calcimimetics, and phosphate-binding drugs) (table 1 supplementary). In multiple regression models we included all factors that were associated with the outcome in univariate analyses.

Time-to-event analysis for all-cause mortality related to DM was performed by the KaplanMeier method. To infer the involvement of DM in the pathophysiological pathway leading to death we applied an analytical approach (10): We estimated the independent relationship between DM and mortality by multiple Cox proportional-hazard models of increasing complexity. In the unadjusted analysis (Model 1) we included DM alone. In Model 2 we introduced DM patients plus potential confounders hypertension, angina, myocardial infarction, age, BMI, dialysis vintage. Finally, to unravel the potential pathogenic pathway by which diabetes mellitus could increase the mortality risk in dialysis patients we added into the multivariate Cox regression analysis two potential mediators 
(that is, variables potentially involved in the pathogenesis pathway between the exposure and the outcome) of such an effect. Such mediators were peripheral vascular disease (Model 3) and warfarin (Model 4). The proportionality assumption was assessed by visual inspection and no violation was found. Hazard ratio (HR) and 95\% confidence intervals (CIs) were calculated.

All statistical analyses were performed using SAS statistical package (version 9.3, SAS, Cary, NC).

\section{Results}

Main demographic and clinical characteristics of the study population are summarized in table 1. Patients with DM $(85,22 \%$; 31 males, 54 females) had higher BMI than patients without DM (27.62 vs 23.94, $\mathrm{p}<0.001)$. No significant differences between the two groups were observed as for age and smoking. Patients with DM had a shorter history of dialysis (37.0 vs 54.5 months; p<0.001), and a higher prevalence of hypertension (90.6\% vs $75.2 \%$; $=0.002)$, myocardial infarction $(27.1 \%$ vs $16.6 \%$; $\mathrm{p}=0.029$ ), and aortic and peripheral vascular disease (table 2). In DM patients, mild to severe aortic calcifications were more frequently observed than in patients without DM (90.6\% vs $77.8 \%, \mathrm{p}=0.008$ ) and this was also true for iliac calcifications. In particular, severe iliac calcifications were significantly worse in DM $(9.4 \%$ vs $2.7 \%, \mathrm{P}=0.006)$.

\section{Diabetes Mellitus, total BGP and ucBGP}

Patients with compared to without DM had significant lower levels of total BGP (139.00 vs. $202.50 \mathrm{mcg} / \mathrm{L}, \mathrm{p}<0.001)$, ucBGP (9.24 vs. $11.32 \mathrm{mcg} / \mathrm{L}, \mathrm{p}=0.022)$, and 25(OH) vitamin D (23.4 vs. $30.2 \mathrm{ng} / \mathrm{ml}, \mathrm{p}<0.001$ ) (table 1, fig 1).

Lower total BGP levels were associated with aortic calcification $(p<0.001)$, iliac calcification $(\mathrm{p}=0.01)$ and vertebral fractures $(\mathrm{p}<0.01)$. In DM patients in treatment with warfarin $(\mathrm{n}=16,8.8 \%)$, total BGP and ucMGP were significantly lower $(56.2$ vs. $152 \mathrm{mcg} / \mathrm{L}, \mathrm{p}<0.001$ and 336 vs. 616 $\mathrm{nmol} / \mathrm{L}, \mathrm{p}=0.038$ ), respectively (supplementary table 2 ).

The regression model showed that DM patients had a statistically significant reduction of $19 \%$ of geometric mean both of total BGP (parameter estimate=-0.21092; $\mathrm{p}=0.009 ; \mathrm{R}^{2}=0.53$ ) and of $25.6 \%$ of geometric mean of ucBGP (parameter estimate $=-0.29634 ; \mathrm{p}=0.034 ; \mathrm{R}^{2}=0.17$ ), (table 3 , table 4 ).

\section{Survival Analysis}

A total of 77 patients died during the follow-up (average time of observation: $2.7 \pm 0.5$ years). Most patients died of cardiovascular events $(n=49)$; other causes were infections $(n=11)$, cancer $(n=5)$ and 
miscellaneous $(n=12)$. Kaplan-Meier survival analysis showed that patients with DM had a lower probability of survival when compared to those with no DM (Fig. 2) and the difference was of high statistical significance ( $\log$ Rank Test, $\mathrm{p}=0.0013$ ). Accordingly, on univariate Cox regression analysis, DM patients had a higher risk of all-cause mortality (HR: 1.83, 95\% CI: 1.13-2.96, p=0.014) (fig 2). Data adjustment for confounders (hypertension, angina, myocardial infarction, age, BMI, dialysis vintage $)$ confirmed the link between DM and mortality $(\mathrm{HR}=1.7395 \% \mathrm{CI} 1.03-2.90 \mathrm{p}=0.038)$ (table 5, model 2). In models including peripheral vascular disease alone (table 5, model 3; HR=1.43 95\% CI 0.82-2.48 $\mathrm{p}=0.206$ ) or in combination with warfarin (table 5, model 4; HR=1.31 95\% CI 0.75-2.28 $\mathrm{p}=0.342$ ), the DM-mortality link was not significant. Of note, forcing total BGP or ucBGP into the model 4 in table 5, did not affect the DM-mortality link which remained not significant (P $\geq 0.28$ ). In these models, neither total BGP (HR: 1.00, 95\% CI: 0.99-1.01, P=0.36) nor ucBGP (HR: $0.99,95 \%$ CI: $0.98-1.01, \mathrm{P}=0.33$ ) significantly predicted the study outcome.

\section{Discussion}

Our study shows a significant reduction of total and ucBGP levels in patients affected by DM and $\mathrm{CKD}$, in contrast to other patients affected by different nephropathies, confirmed in the regression model.

We know that BGP is not only involved in bone matrix mineralization, but it is also a mediator in endocrine pathway. The endocrine role of BGP seems to be related to its undercarboxylated form, while the process of carboxylation is necessary for the protein activation in bone tissue (11). Endocrine functions are strictly connected with glucose metabolism, thus preponderant for bone metabolism in DM patients. The endocrine role consists in regulating glucose homeostasis by promoting the secretion of insulin from pancreatic beta-cells and by increasing adiponectine expression, an anti-inflammatory protein secreted by adipocytes. These actions finally result into a greater insulin sensitivity. In fact, in mice, administration of ucOC was able to increase the insulin and adiponectin secretion and stimulated glucose and lipid catabolism (12). BGP requires vitamin K for its activity. Clinical trials have reported contrasting results about the effects of vitamin $\mathrm{K}$ on insulin sensitivity. A recent meta-analysis including eight trials involving 1,077 participants suggested no effect of vitamin K supplementation on insulin sensitivity (13). In contrast, other authors reported that Vitamin K2 administration could improve glycemic status in DM rats by induction of BGP gene expression (14). Moreover, Choi et al. found a positive effect of vitamin K2 supplementation in increasing insulin sensitivity in healthy young men via BGP metabolism (15). According to the literature, in our DM population aortic and iliac calcifications were significantly more prevalent than in patients without DM. Vascular calcifications are considered strong predictors of cardiovascular disease, closely connected with morbidity and mortality (8). Evidence indicates that 
vascular calcification is a process of active bone formation regulated by stimulators and inhibitors of calcification. BGP is known to be involved in preventing vascular aortic calcifications, through direct and indirect mechanisms. Indirect mechanisms are mediated by its action on insulin, in particular in the context of metabolic acidosis associated to bone reabsorption, very common in the CKD population, or by the release of adiponectin. Adiponectin may prevent the trans-differentiation of vascular smooth muscle cells into osteoblast-like cells in arterial vessels (16). Data are available not only in rats with CKD, but also in humans. In fact, higher total BGP levels were found associated with lower abdominal aortic calcification progression rate and lower mortality in a 10 year-long prospective study in elderly Caucasian subjects, showing total BGP as an independent factor of cardiovascular risk and mortality (17). Moreover, in the hemodialysis population we showed that low levels of total-BGP are associated with vertebral fractures, aortic and iliac calcifications (5). Finally, a recent review reported low BGP levels as a biomarker of abdominal aortic calcification in patients with diabetes (18).

In the univariate Cox regression analysis, DM patients were found to have a higher risk of all-cause mortality $(\mathrm{p}=0.014)$. Although we did not find that BGP levels predict mortality, we cannot exclude that their lower levels may lead to a reduced protection of bone and vascular health, increasing cardiovascular mortality. Regarding crude and adjusted HR for all-cause mortality in relation to DM (table 5), data adjustment for possible confounders (hypertension, angina, myocardial infarction, age, BMI, dialysis vintage) did not affect the significant link between DM and mortality, indicating that this association cannot be explained by confounding factors themselves. Thus, we would like to underline that when we forced into the model two other factors - vascular calcifications and warfarin - the association between DM and mortality became not significant, suggesting that vascular calcifications and warfarin use may be mediators but not confounders in the potential pathogenic pathways underlying the relationship between DM and mortality.

Finally, in the sub-analysis regarding warfarin treated DM patients, we observed reduced levels of BGP and ucMGP. The association of lower serum ucMGP, rather than total MGP, with atherosclerosis and vascular calcification has been previously reported in the CKD population (9). In a study conducted in patients affected with cardiovascular disease, Parker et al. reported that reduced kidney function was associated with lower serum ucMGP levels, suggesting MGP as a potential marker of vascular calcification and cardiovascular disease in the CKD population (19). Warfarin, acting as a vitamin $\mathrm{K}$ antagonist, may inhibit vitamin-K dependent proteins that are involved in bone mineralization and the prevention of vascular calcification, including BGP and MGP. We already reported that in hemodialysis patients warfarin use was associated with an increase of aortic and iliac calcifications, with significantly lower BGP levels, and ucMGP levels (20). 
DM and CKD patients have a high prevalence of low vitamin D levels and our study also 231 shows a significant reduction of vitamin D levels in DM patients. Recent evidence suggested the important role of vitamin D in the pathogenesis of DM and CKD, reporting that low vitamin D levels are associated with poor outcomes, in particular with progression of DM and cardiovascular disease 234 low 25(OH) vitamin D levels and severe vascular calcifications, assuming a possible protective role of vitamin D on vascular calcifications by its action on vitamin $\mathrm{K}$ dependent proteins, such as BGP and MGP (6). In our previous study we showed that vitamin D analogues can improve vitamin $\mathrm{K}$ dependent protein levels. In particular, administration of vitamin D was associated with increased BGP levels in hemodialysis patients (22). These data support the potential role of vitamin D supplementation as a preventative and therapeutic agent for bone and vascular health in DM and CKD patients.

Finally, we underscore the interesting associations of total BGP with PTH and ALP, which could be explained by two factors: Vitamin D control on BGP (low vitamin D levels in DM patients could damage this function) and a higher bone turnover, resulting in higher BGP and ucBGP. All of this reveals a remarkable role of BGP as bone biomarker in the scenery of CKD-MBD.

In conclusions, in hemodialysis patients we confirmed an increased mortality associated to DM and we found an association between diabetic status and decreased BGP levels. To our knowledge, this is the first study in hemodialysis patients suggesting a potential protective role of BGP in the context of bone, endocrine and vascular pathway. Further investigations are needed to assess the clinical implications of low BGP levels in hemodialysis patients affected by DM.

\section{Disclosures}

All authors state that they have no conflicts of interest. 


\begin{tabular}{|c|c|c|c|}
\hline & $\begin{array}{c}\text { Patients } \\
\text { With DM } \\
(\mathrm{n}=\mathbf{8 5}, \mathbf{2 2 \%})\end{array}$ & $\begin{array}{c}\text { Patients } \\
\text { Without DM } \\
(\mathrm{n}=302, \mathbf{7 8 \%})\end{array}$ & p-value \\
\hline Gender, female, n (\%) & $31(36.5 \%)$ & $114(37.7 \%)$ & 0.830 \\
\hline Age, years, median & $68(63,73.50)$ & $67(52,74)$ & 0.132 \\
\hline Weight, kg, median & $76.50(67.75,87.75)$ & $67(58.5,75.63)$ & $<0.001$ \\
\hline Height, m, median & $1.65(1.60,1.75)$ & $1.68(1.60,1.73)$ & 0.491 \\
\hline BMI, $\mathrm{kg} / \mathrm{cm}^{2}$, median & $27.62(24.42,30.89)$ & $23.94(21.29,26.72)$ & $<0.001$ \\
\hline Smokers, $\mathrm{n}(\%)(\mathrm{n}=370)$ & & & 0.186 \\
\hline Yes & $47(57.3 \%)$ & $187(64.9 \%)$ & \\
\hline No & $25(30.5 \%)$ & $60(20.8 \%)$ & \\
\hline Ex & $10(12.2 \%)$ & $41(14.3 \%)$ & \\
\hline Current or former alcohol drinkers, $n(\%)(n=361)$ & $62(21.8 \%)$ & $20(26 \%)$ & 0.442 \\
\hline
\end{tabular}

\section{$\underline{\text { Medical history }}$}

Dialysis vintage, months, median

$37(26,58)$

$54.5(29.75,113.25)$

$<0.001$

Type of dialysis, $\mathrm{n}(\%)$

0.138

Bicarbonate dialysis

$34(40.0 \%)$

$155(51.3 \%)$

Hemofiltration (HF)

$11(12.9 \%)$

$21(7 \%)$

Hemodiafiltration (HDF)

$21(24.7 \%)$

$81(26.8 \%)$

Acetate free biofiltration (AFB)

$16(18.8 \%)$

$38(12.6 \%)$

Other types of dialysis

$3(3.6 \%)$

$7(2.3 \%)$ 


\begin{tabular}{|c|c|c|c|}
\hline & $\begin{array}{c}\text { Patients } \\
\text { With DM } \\
(\mathrm{n}=\mathbf{8 5}, \mathbf{2 2 \%})\end{array}$ & $\begin{array}{c}\text { Patients } \\
\text { Without DM } \\
(n=302,78 \%)\end{array}$ & p-value \\
\hline Previous kidney transplant, $\mathrm{n}(\%)$ & $2(2.4 \%)$ & $52(17.2 \%)$ & $<0.001$ \\
\hline Hypertension, $\mathrm{n}(\%)$ & $77(90.6 \%)$ & $227(75.2 \%)$ & 0.002 \\
\hline Angina, $\mathrm{n}(\%)$ & $19(22.4 \%)$ & $45(14.9 \%)$ & 0.102 \\
\hline Myocardial infarction, $\mathrm{n}(\%)$ & $23(27.1 \%)$ & $50(16.6 \%)$ & 0.029 \\
\hline Atrial fibrillation, $\mathrm{n}(\%)$ & $14(16.5 \%)$ & $37(12.3 \%)$ & 0.310 \\
\hline Heart failure, $\mathrm{n}(\%)$ & $10(11.8 \%)$ & $29(9.6 \%)$ & 0.559 \\
\hline Peripheral vascular disease, $\mathrm{n}(\%)$ & & & $<0.001$ \\
\hline No & $33(38.8 \%)$ & $220(72.8 \%)$ & \\
\hline Asymptomatic & $32(37.6 \%)$ & $66(21.9 \%)$ & \\
\hline Intermittent claudication & $12(14.1 \%)$ & $16(5.3 \%)$ & \\
\hline Amputation & $8(9.5 \%)$ & $0(0 \%)$ & \\
\hline Cerebrovascular accident, $\mathrm{n}(\%)$ & & & 0.958 \\
\hline No & $76(89.4 \%)$ & $270(89.4 \%)$ & \\
\hline Stroke & $4(4.7 \%)$ & $16(5.3 \%)$ & \\
\hline Other type & $5(5.9 \%)$ & $16(5.3 \%)$ & \\
\hline Vertebral fractures, $\mathrm{n}(\%)$ & $44(51.8 \%)$ & $170(56.3 \%)$ & 0.458 \\
\hline Vertebral fractures among men, $\mathrm{n}(\%)$ & $30(55.6 \%)$ & $115(61.2 \%)$ & 0.458 \\
\hline Vertebral fractures among women, $\mathrm{n}(\%)$ & $14(45.2 \%)$ & $55(48.2 \%)$ & 0.760 \\
\hline
\end{tabular}




\section{Patients}

With DM

$(\mathrm{n}=85,22 \%)$

\section{Patients}

Without DM

$(\mathrm{n}=302, \mathbf{7 8 \%}) \quad$ p-value $\underline{\text { Routine biochemical profile }}$

$\mathrm{Ca}, \mathrm{mg} / \mathrm{dl}$, median

$\mathrm{Ca}, \mathrm{mg} / \mathrm{dl}$, mean $\pm \mathrm{SD}$ (not normally distributed)

$\mathrm{P}, \mathrm{mg} / \mathrm{dl}$, mean $\pm \mathrm{SD}$ (not normally distributed)

$\mathrm{P}, \mathrm{mg} / \mathrm{dl}$, median

Alkaline phosphatase, U/L, median

PTH, pg/ml, median

Albumin, g/dl, median

CRP, mg/L, median

$\mathrm{KT} / \mathrm{V}$, mean $\pm \mathrm{SD}$

Aluminium, mcg/L, median

Total cholesterol, mg/dl, median

Triglycerides, mg/dl, median

HDL Cholesterol, mg/dl, median

LDL Cholesterol, mg/dl, median

25(OH)D, ng/mL, median

BGP total, mcg/L, median

ucBGP, mcg/L, median
$9.0(8.7,9.4)$

$9.08 \pm 0.59$

$4.63 \pm 1.07$

$4.34(3.85,5.35)$

$87(65,111.5)$

$207(135.5,340)$

$3.9(3.5,4.0)$

$2.13(0.47,4.1)$

$1.26 \pm 0.25$

$10(7,16)$

$176(150,197.2)$

$157(111.5,211)$

$39(32,49)$

$96(74,119)$

$23.4(16.5,34.7)$

$139(62.40,220.5)$

$9.24(2.99,15.54)$
$9.1(8.7,9.6)$

0.176

$9.18 \pm 0.70$

0.225

$4.80 \pm 1.32$

0.272

$4.65(3.88,5.59)$

0.338

$81(64,111)$

0.432

$244.5(140,401.25)$

0.169

$3.9(3.5,4.1)$

0.248

$1.65(0.50,5.26)$

0.802

$1.25 \pm 0.27$

0.633

$13.8(8,22)$

0.057

$165(140,192.3)$

0.164

$146.5(110,202.3)$

0.349

$40(33,50)$

0.652

$89(69,116)$

0.513

$30.2(20.18,46.78)$

$<0.001$

$202.5(109,362)$

$<0.001$

$11.32(6.15,18.15)$

0.022 


\begin{tabular}{|c|c|c|c|}
\hline & $\begin{array}{c}\text { Patients } \\
\text { With DM } \\
(\mathrm{n}=\mathbf{8 5}, \mathbf{2 2 \%})\end{array}$ & $\begin{array}{c}\text { Patients } \\
\text { Without DM } \\
(\mathrm{n}=\mathbf{3 0 2}, \mathbf{7 8 \%})\end{array}$ & p-value \\
\hline MGP total, nmol/L, median & $18(12,31.88)$ & $19.36(13,30.73)$ & 0.582 \\
\hline ucMGP, nmol/L, median & $541.86(287.40,981.5)$ & $572.84(285,930)$ & 0.634 \\
\hline $\mathrm{Mg}, \mathrm{mg} / \mathrm{dL}$, median & $(\mathrm{n}=26) 2.3(2,2.6)$ & $(n=113) 2.3(2,2.7)$ & 0.488 \\
\hline
\end{tabular}

265

266

267 
268 Table 2. Presence and severity of vascular calcifications in patients with DM.

Patients

With DM

$(\mathrm{n}=\mathbf{8 5}, \mathbf{2 2 \%})$

Aortic calcifications, n (\%)

None

Mild + Moderate

Severe

Aortic calcifications: mild, moderate or severe

vs none, $\mathrm{n}(\%)$

$77(90.6 \%)$
Patients

No DM

$(\mathrm{n}=\mathbf{3 0 2}, \mathbf{7 8 \%})$

p-value

0.029

$\begin{array}{cc}8(9.4 \%) & 67(22.2 \%) \\ 47(55.3 \%) & 149(49.3 \%) \\ 30(35.3 \%) & 86(28.5 \%)\end{array}$

$235(77.8 \%)$

0.008

0.012

$31(36.5 \%) \quad 139(46 \%)$

$46(54.1 \%) \quad 155(51.3 \%)$

$8(9.4 \%) \quad 8(2.7 \%)$ 
Fig. 1. Boxplot of ucBGP, Total BGP and 25(OH)D grouped by DM.
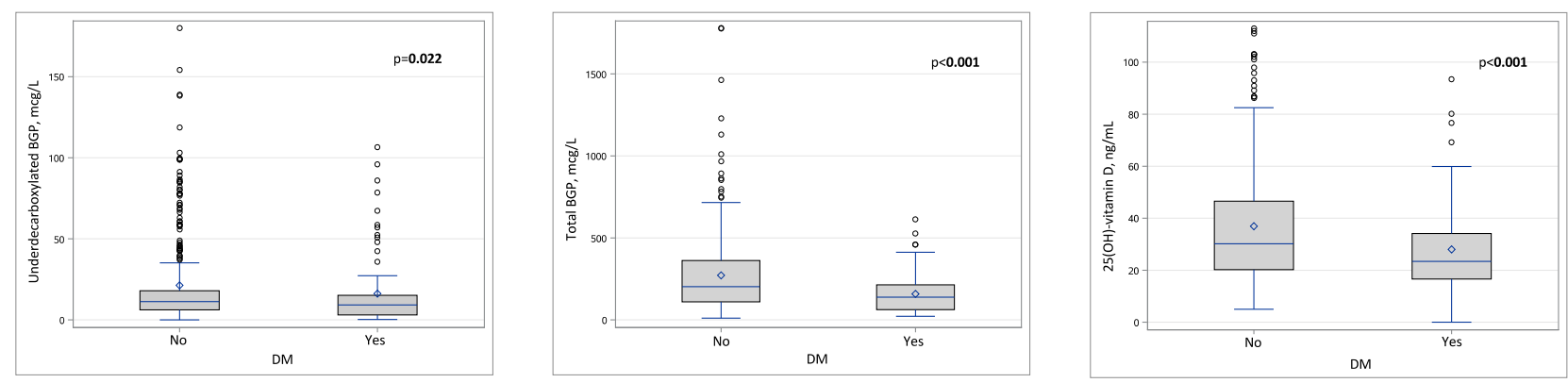

290

291

292 
293 Table 3. Regression model with outcome total BGP (log-transformed).

\begin{tabular}{|c|c|c|}
\hline VARIABLE & $\begin{array}{c}\text { PARAMETER ESTIMATE } \\
(\mathrm{b})\end{array}$ & P-VALUE \\
\hline $\mathrm{DM}$ & -0.21 & $\mathbf{0 . 0 0 9}$ \\
\hline $\operatorname{lgPTH}$ & 0.27 & $<\mathbf{0 . 0 0 0 1}$ \\
\hline $\lg \mathrm{ALP}$ & 0.29 & $<\mathbf{0 . 0 0 0 1}$ \\
\hline
\end{tabular}

295 The stepwise analysis also identified the following variables as covariates: age, BMI, smoking status, cerebrovascular accidents, hypertension, heart failure, vascular calcification, LDL cholesterol, albumin and the following therapies: aluminium, warfarin, calcimimetics, vitamin D analogues, intravenous calcitriol and antibiotics. Other variables remained out of the model. 
Table 4. Regression model with outcome ucBGP (log-transformed).

\begin{tabular}{|l|c|c|}
\hline VARIABLE & PARAMETER ESTIMATE $(\mathrm{b})$ & P-VALUE \\
\hline DM & -0.30 & $\mathbf{0 . 0 3 4}$ \\
\hline $\lg \mathrm{PTH}$ & 0.22 & $\mathbf{0 . 0 0 1 1}$ \\
\hline
\end{tabular}

The stepwise analysis also identified the following variables as covariates: phosphate, aortic calcifications, calciumphosphate, KT/V, liver disease and the following therapies: intravenous calcitriol, calcimimetics, heparin, warfarin, steroids and antiepileptics. Other variables remained out of the model.

Fig. 2. Kaplan-Meier survival curves for all-cause mortality, for patients with DM (1, red line) and patients 309 with no DM (0, blu line).

310

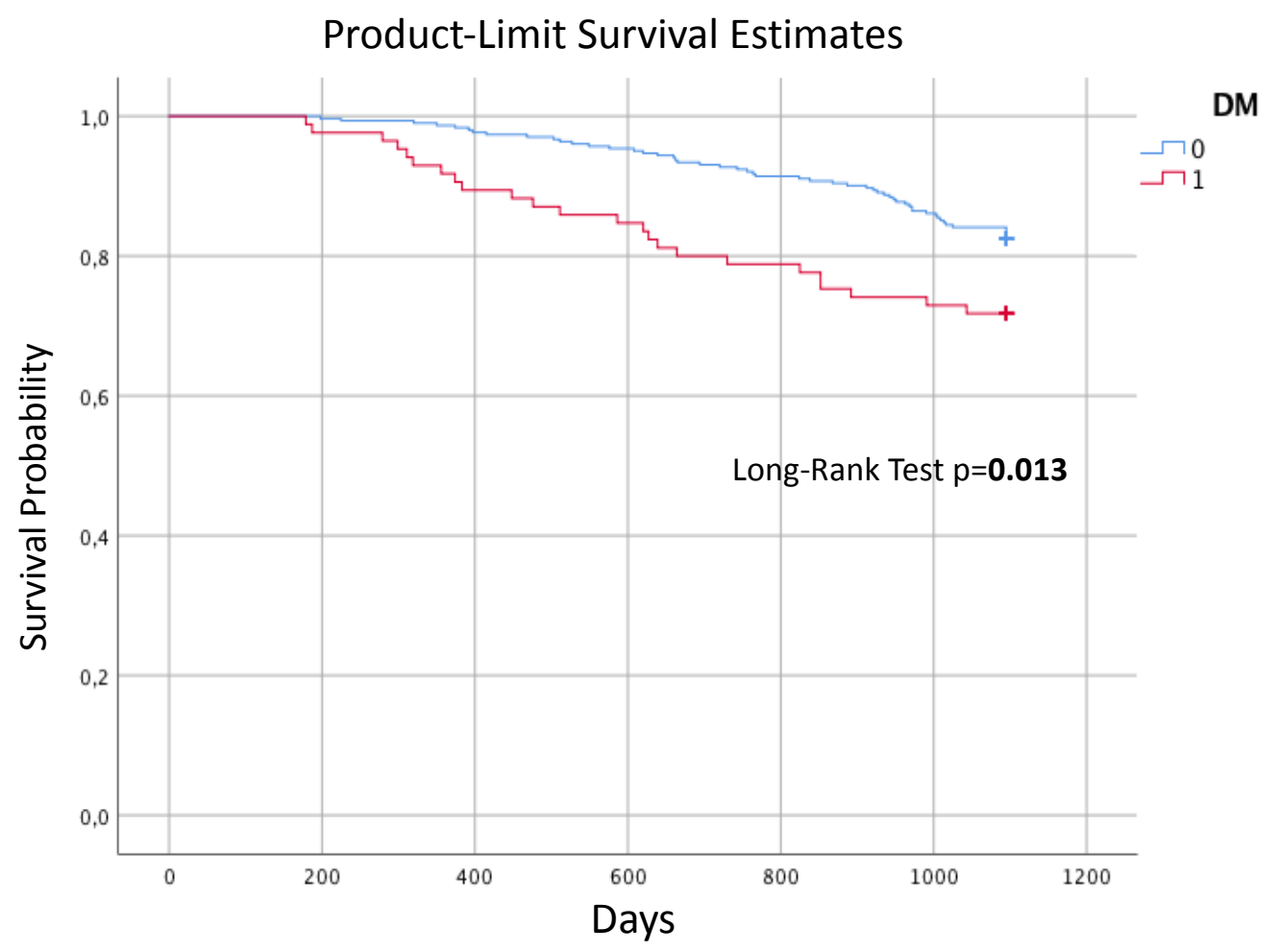


319 Table 5. Crude and adjusted HR for all-cause mortality in relation to DM.

\begin{tabular}{|l|l|l|l|l|}
\hline & Model 1 (Unadjusted) & $\begin{array}{l}\text { Model 2 } \\
\text { (Adjusted for } \\
\text { confounders*) }\end{array}$ & $\begin{array}{l}\text { Model 3 } \\
\text { (Adjusted for } \\
\text { confounders* } \\
\text { and peripheral } \\
\text { vascular } \\
\text { disease) }\end{array}$ & $\begin{array}{l}\text { Model 4 (Adjusted for } \\
\text { confounders*, peripheral } \\
\text { vascular disease and } \\
\text { warfarin) }\end{array}$ \\
\hline $\begin{array}{l}\text { Patients with } \\
\text { DM }\end{array}$ & $\begin{array}{l}\text { HR=1.83 95\% CI 1.13- } \\
2.96 \mathbf{p = 0 . 0 1 4}\end{array}$ & $\begin{array}{l}\text { HR=1.73 95\% CI } \\
1.03-2.90 \mathbf{p = 0 . 0 3 8}\end{array}$ & $\begin{array}{l}\text { HR=1.43 95\% CI } \\
0.82-2.48 \\
\mathrm{p}=0.206\end{array}$ & $\begin{array}{l}\text { HR=1.31 95\% CI 0.75- } \\
2.28 \mathrm{p}=0.342\end{array}$ \\
\hline
\end{tabular}

$321 *$ Confounders: hypertension, angina, myocardial infraction, age, BMI, dialysis vintage.

$322 \mathrm{CI}=$ Confidence Interval; HR $=$ Hazard Ratio. 


\section{Patients}

Drugs prescribed to patients

Warfarin (n, \%)

Steroids (n, \%)

Thyroid hormones (n, \%)

Antibiotics (n, \%)

Antiepileptics (n, \%)

Statins (n, \%)

Beta-Blockers (n, \%)

Antidiabetics (n, \%)

Insulin (n, \%)

Anti-Gastric (n, \%)

Aluminium (n, \%)

Calcium carbonate (n, \%)

Calcium acetate (n, \%)

Sevelamer (n, \%)

Lanthanum (n, \%)

Oral calcitriol (n, \%)

Intravenous calcitriol (n, \%)
With DM

$(\mathrm{n}=\mathbf{8 5}, \mathbf{2 2 \%})$

$16(18.8 \%)$

$2(2.4 \%)$

$11(12.9 \%)$

$8(9.4 \%)$

$4(4.7 \%)$

$40(47.1 \%)$

$32(37.6 \%)$

$7(8.2 \%)$

$58(68.2 \%)$

$64(75.3 \%)$

$16(18.8 \%)$

$35(41.2 \%)$

$9(10.6 \%)$

$38(44.7 \%)$

$10(11.8 \%)$

$43(50.6 \%)$

$2(2.4 \%)$

\section{Patients}

Without DM

$(\mathrm{n}=302,78 \%) \quad$ p-value

$30(9.9 \%)$

0.025

$19(6.3 \%)$

0.157

$29(9.6 \%)$

0.372

$8(2.6 \%)$

0.006

$10(3.3 \%)$

0.543

$86(28.5 \%)$

0.001

$112(37.1 \%)$

0.925

$$
0(0 \%)
$$

$<0.001$

$0(0 \%)$

$<0.001$

$233(77.2 \%)$

0.720

$80(26.5 \%)$

0.148

$97(32.1 \%)$

0.120

$12(4.0 \%)$

0.017

$125(41.4 \%)$

0.584

$46(15.2 \%)$

0.422

$134(44.4 \%)$

0.309

$134(44.4 \%)$

0.653 
Vitamin D analogues (n, \%)

Calcimimetics (n, \%)
$12(14.1 \%)$

$11(12.9 \%)$
$65(21.5 \%)$

0.131

328 
329 Table 2 supplementary. Main characteristics of the Patients With DM and Warfarin VS Patients With DM

330 and No Warfarin Use.

\begin{tabular}{|c|c|c|c|}
\hline & $\begin{array}{c}\text { Patients } \\
\text { With DM and } \\
\text { Warfarin Use } \\
(\mathbf{n}=\mathbf{1 6}, \mathbf{1 8 . 8 \%})\end{array}$ & $\begin{array}{c}\text { Patients } \\
\text { With DM and No } \\
\text { Warfarin Use } \\
(\mathbf{n}=69, \mathbf{8 1 . 2 \%})\end{array}$ & p-value \\
\hline Gender, female, n (\%) & $8(50 \%)$ & $23(33.3 \%)$ & 0.212 \\
\hline Age, years, median & $72(64.5,77.50)$ & $67(63,72)$ & 0.095 \\
\hline Weight, kg, median & $75.25(61.25,81.0)$ & $76.5(69,88)$ & 0.220 \\
\hline Height, m, median & $1.65(1.60,1.78)$ & $1.66(1.62,1.75)$ & 0.596 \\
\hline BMI, $\mathrm{kg} / \mathrm{cm}^{2}$, median & $26.17(23.04,28.05)$ & $28.26(24.65,31.45)$ & 0.144 \\
\hline Smoker, $\mathrm{n}(\%)(\mathrm{n}=370)$ & & & 0.429 \\
\hline Yes & $10(62.4 \%)$ & $37(56.1 \%)$ & \\
\hline No & $3(18.8 \%)$ & $22(33.3 \%)$ & \\
\hline Ex & $3(18.8 \%)$ & $7(10.6 \%)$ & \\
\hline Current or former alcohol drinker, $\mathrm{n}(\%)(\mathrm{n}=77)$ & $3(18.8 \%)$ & $17(27.9 \%)$ & 0.459 \\
\hline
\end{tabular}

Medical history

Dialysis vintage, months, median

$42(25,61.5)$

$37(26,55)$

0.723

Type of dialysis, $\mathrm{n}(\%)$

0.622

Bicarbonate dialysis

$6(37.5 \%)$

$28(40.6 \%)$

Hemofiltration (HF)

$2(12.5 \%)$

$9(13.0 \%)$

Hemodiafiltration (HDF)

$3(18.8 \%)$

$18(26.1 \%)$

Acetate free biofiltration (AFB)

$5(31.2 \%)$

$11(16 \%)$

Other types of dialysis

$0(0 \%)$

$3(4.3 \%)$ 


\begin{tabular}{|c|c|c|c|}
\hline & $\begin{array}{c}\text { Patients } \\
\text { With DM and } \\
\text { Warfarin Use } \\
(\mathrm{n}=\mathbf{1 6}, \mathbf{1 8 . 8 \%})\end{array}$ & $\begin{array}{c}\text { Patients } \\
\text { With DM and No } \\
\text { Warfarin Use } \\
(\mathbf{n}=69,81.2 \%)\end{array}$ & p-value \\
\hline Previous kidney transplant, $\mathrm{n}(\%)$ & $1(6.3 \%)$ & $1(1.5 \%)$ & 0.254 \\
\hline Hypertension, n (\%) & $14(87.5 \%)$ & $63(91.3 \%)$ & 0.639 \\
\hline Angina, $\mathrm{n}(\%)$ & $5(31.3 \%)$ & $14(20.3 \%)$ & 0.343 \\
\hline Myocardial infarction, $\mathrm{n}(\%)$ & $2(12.5 \%)$ & $21(30.4 \%)$ & 0.146 \\
\hline Atrial fibrillation, $\mathrm{n}(\%)$ & $9(56.3 \%)$ & $5(7.3 \%)$ & $<0.001$ \\
\hline Heart failure, n (\%) & $2(12.5 \%)$ & $811.6 \%)$ & 0.919 \\
\hline Peripheral vascular disease, $\mathrm{n}(\%)$ & & & 0.420 \\
\hline No & $7(43.8 \%)$ & $26(37.7 \%)$ & \\
\hline Asymptomatic & $4(25 \%)$ & $28(40.6 \%)$ & \\
\hline Intermittent claudication & $4(25 \%)$ & $8(11.6 \%)$ & \\
\hline Amputation & $1(6.2 \%)$ & $7(10.1 \%)$ & \\
\hline Cerebrovascular accident, $\mathrm{n}(\%)$ & & & 0.301 \\
\hline No & $14(87.5 \%)$ & $62(89.8 \%)$ & \\
\hline Stroke & $0(0 \%)$ & $4(5.8 \%)$ & \\
\hline Other type & $2(12.5 \%)$ & $3(4.4 \%)$ & \\
\hline Vertebral fractures, n (\%) & $8(50.0 \%)$ & $36(52.2 \%)$ & 0.875 \\
\hline Vertebral fractures among men, $\mathrm{n}(\%)$ & $6(75 \%)$ & $24(52.2 \%)$ & 0.230 \\
\hline Vertebral fractures among women, $\mathrm{n}(\%)$ & $2(25 \%)$ & $12(52.2 \%)$ & 0.183 \\
\hline
\end{tabular}




\begin{tabular}{|c|c|c|c|}
\hline & $\begin{array}{c}\text { Patients } \\
\text { With DM and } \\
\text { Warfarin Use } \\
(\mathbf{n}=\mathbf{1 6}, \mathbf{1 8 . 8 \%})\end{array}$ & $\begin{array}{c}\text { Patients } \\
\text { With DM and No } \\
\text { Warfarin Use } \\
(\mathbf{n}=69,81.2 \%)\end{array}$ & p-value \\
\hline \multicolumn{4}{|l|}{$\underline{\text { Routine biochemical profile }}$} \\
\hline $\mathrm{Ca}, \mathrm{mg} / \mathrm{dl}$, median & $8.94(8.55,9.3)$ & $9.04(8.7,9.4)$ & 0.525 \\
\hline $\mathrm{Ca}, \mathrm{mg} / \mathrm{dl}$, mean $\pm \mathrm{SD}$ (not normal distributed) & $9.02 \pm 0.69$ & $9.09 \pm 0.57$ & 0.637 \\
\hline $\mathrm{P}, \mathrm{mg} / \mathrm{dl}$, mean $\pm \mathrm{SD}$ (not normal distributed) & $4.83 \pm 0.86$ & $4.58 \pm 1.12$ & 0.209 \\
\hline $\mathrm{P}, \mathrm{mg} / \mathrm{dl}$, median & $4.83(4.15,5.60)$ & $4.34(3.80,5.2)$ & 0.192 \\
\hline Alkaline phosphatase, $\mathrm{U} / \mathrm{L}$, median & $85(48,124.5)$ & $87(65,110)$ & 0.601 \\
\hline PTH, pg/ml, median & $263(104.5,445)$ & $206(142,321.3)$ & 0.702 \\
\hline Albumin, $\mathrm{g} / \mathrm{dl}$, median & $3.85(3.3,4.0)$ & $3.9(3.5,4.1)$ & 0.357 \\
\hline $\mathrm{CRP}, \mathrm{mg} / \mathrm{L}$, median & $2.5(0.36,11.6)$ & $1.90(0.50,4.0)$ & 0.725 \\
\hline $\mathrm{KT} / \mathrm{V}$, median & $1.21(1.05,1.54)$ & $1.26(1.10,1.37)$ & 0.951 \\
\hline Aluminium, mcg/L, median & $13(10,30)$ & $9(7,15)$ & 0.132 \\
\hline Total cholesterol, mg/dl, median & $181.5(161,205.5)$ & $173(150,193)$ & 0.331 \\
\hline Triglycerides, mg/dl, median & $143.5(122.5,214.5)$ & $161(110,211)$ & 0.698 \\
\hline HDL Cholesterol, mg/dl, median & $40.5(32.5,55.5)$ & $39(32,47)$ & 0.396 \\
\hline LDL Cholesterol, mg/dl, median & $105(76,118)$ & $94.5(69,119)$ & 0.409 \\
\hline 25(OH)D, median & $23.9(16.5,47.7)$ & $23.2(16.6,32.6)$ & 0.589 \\
\hline BGP total, mcg/L, median & $56.2(37.40,121.6)$ & $152(74.8,230)$ & $<0.001$ \\
\hline ucBGP, mcg/L, median & $12.93(6.1,51.59)$ & $7.94(2.94,13.42)$ & 0.064 \\
\hline
\end{tabular}




\begin{tabular}{lccc} 
& $\begin{array}{c}\text { Patients } \\
\text { With DM and } \\
\text { Warfarin Use } \\
(\mathbf{n = 1 6 , 1 8 . 8 \% )}\end{array}$ & $\begin{array}{c}\text { Patients } \\
\text { With DM and No } \\
\text { Warfarin Use } \\
\mathbf{( n = 6 9 , 8 1 . 2 \% )}\end{array}$ & p-value \\
\hline MGP total, nmol/L, median & $16.72(11.46,24.12)$ & $18.42(12,34.52)$ & 0.507 \\
ucMGP, nmol/L, median & $336.00(143,590)$ & $616(310.42,1062)$ & $\mathbf{0 . 0 3 8}$ \\
Mg, mg/dL, median & & & \\
& $(\mathrm{n}=26) 2.75(2.7,2.8)$ & & \\
& & &
\end{tabular}

331

332

333 


\section{REFERENCES}

1) Winocour PH. Diabetes and chronic kidney disease: an increasingly common multi-morbid disease in need of a paradigm shift in care. Diabet Med 2018; 35: 300-305.

2) Patti A, Gennari L. Endocrine actions of osteocalcin. Int J Endocrinol 2013; 2013:1-10.

3) Neve A, Corrado A, Cantatore FP. Osteocalcin: skeletal and extraskeletal effects. J Cell Physiol 2013; 228:1149-53.

4) Bacchetta J, Boutroy S, Guebre-Egziabher F, et al. The relationship between adipokines, osteocalcin and bone quality in chronic kidney disease. Nephrol Dial Transplant 2009; 24: 3120-5.

5) Fusaro M, Gallieni M, Noale M, et al. The relationship between the Spine Deformity Index, biochemical parameters of bone metabolism and vascular calcifications: results from the Epidemiological VERtebral FRACtures iTalian Study (EVERFRACT) in dialysis patients. Clin Chem Lab Med 2014; 52: 1595-603.

6) Fusaro M. Gallieni M, Rebora P, et al. Atrial fibrillation and low vitamin D levels are associated with severe vascular calcifications in hemodialysis patients. J Nephrol 2016; 29: $419-426$.

7) Shearer MJ. Role of vitamin K and GLA proteins in the pathophysiology of osteoporosis and vascular calcification. Curr Opin Clin Nutr Metab Care 2000; 3: 433-438.

8) Fusaro M, Noale M, Viola V, et al. Vitamin K, vertebral fractures, vascular calcifications, and mortality: vitamin K Italian (VIKI) dialysis study. J Bone Miner Res 2012; 27:22712278

9) Cranenburg EC, Vermeer C, Koos R, et al. The circulating inactive form of matrix Gla Protein (ucMGP) as a biomarker for cardiovascular calcification. J Vasc Res. 2008; 45: 427-436.

10) Kraemer HC, Stice E, Kazdin A, et al. How do risk factors work together? Mediators, moderators, and independent, overlapping, and proxy risk factors. Am J Psychiatry 2001; 158: 848-856.

11) Neve A, Corrado A, Cantatore FP. Osteocalcin: skeletal and extraskeletal effects. J Cell Physiol 2013; 228:1149-53.

12) Ferron M, Hinoi E, Karsenty G, Ducy P. Osteocalcin differentially regulates beta cell and adipocyte gene expression and affects the development of metabolic diseases in wild-type mice. Proc Natl Acad Sci U S A 2008;105:5266-70.

13) Suksomboon N, Poolsup N, Darli Ko Ko H. Effect of vitamin K supplementation on insulin sensitivity: a meta-analysis. Diabetes, Metabolic Syndrome and Obesity: Targets and Therapy 2017:10 169-177. 
14) Hussein AG, Mohamed RH, Shalaby SM, Abd El Motteleb DM. Vitamin K2 alleviates type 2 diabetes in rats by induction of osteocalcin gene expression. Nutrition 2018; 47: 33-38.

15) Choi HJ, Yu J, Choi H, et al. Vitamin K2 supplementation improves insulin sensitivity via osteocalcin metabolism: a placebo-controlled trial. Diabetes Care 2011;34:e147.

16) Luo XH, Zhao LL, Yuan LQ, Wang M, Xie H, Liao EY. Development of arterial calcification in adiponectin-deficient mice: adiponectin regulates arterial calcification. J Bone Miner Res 2009;24:1461-8.

17) Confavreux CB, Szulc P, Casey R, et al. Higher serum osteocalcin is associated with lower abdominal aortic calcification progression and longer 10-year survival in elderly men of the MINOS cohort. J Clin Endocrinol Metab 2013; 98: 1084-92.

18) Bendix EF, Johansen E, Ringgaard T, Wolder M, Starup-Linde J. Diabetes and abdominal aortic calcification - a systematic review. Curr Osteoporos Rep 2018; 16: $42-57$.

19) Parker BD, Ix JH, Cranenburg EC, et al. Association of kidney function and uncarboxylated matrix Gla protein: Data from the Heart and Soul Study. Nephrol Dial Transplant 2009; 24: 2095-2101.

20) Fusaro M, Tripepi G, Noale M, et al. Prevalence of vertebral fractures, vascular calcifications, and mortality in warfarin treated hemodialysis patients. Curr Vasc Pharmacol. 2015;13:24858.

21) Nakashima A, Yokoyama K, Yokoo T, Urashima M. Role of vitamin D in diabetes mellitus and chronic kidney disease. World J Diabetes 2016; 7: 89-100.

22) Fusaro M, Giannini S, Gallieni $M$, et al. Calcimimetic and vitamin $D$ analog use in hemodialyzed patients is associated with increased levels of vitamin $\mathrm{K}$ dependent proteins. Endocrine 2016; 51:333-41. 